$\left.\begin{array}{c}\text { Sournals } \\ \text { ONTERNATIONAL JOURNAL OF } \\ \text { ORGANIZATIONAL LEADERSHIP }\end{array}\right) \begin{gathered}\text { INDUSTRIAL } \\ \text { MANAGEMENT } \\ \text { INSTITUTE }\end{gathered}$

\title{
The impact of SHRM on sustainable organizational learning and performance development
}

\author{
Nibedita Saha $^{{ }^{*}}$, Bani Chatterjee ${ }^{2}$, Aleš Gregar ${ }^{3}$, Petr Sáha ${ }^{1}$ \\ ${ }^{1}$ University Institute, Tomas Bata University in Zlín, Czech Republic \\ ${ }^{2}$ Department of Humanities \& Social Sciences, Indian Institute of Technology, Kharagpur, India \\ ${ }^{3}$ Faculty of Management and Economics, Tomas Bata University in Zlín, Czech Republic
}

\section{Keywords: \\ Organizational Learning, Organizational \\ Performance Development, Strategic Human Resource Management (SHRM), Sustainability}

\section{Received}

9 December 2015

Received in revised form 27 February 2016

Accepted

29 February 2016

Correspondence: nibedita@uni.utb.cz

\section{Abstract}

\begin{abstract}
This article aimed at developing a conceptual framework about the role of Strategic Human Resource Management (SHRM) and its impact on managerial skills and organizational performance which offered some insights into how learning might occur at the organizational level in order to improve organizational capability as well as individual capability. It also indicated that there were plenty of research studies to advocate the influence of SHRM. Nevertheless, there were some rare examples of linkages between SHRM and sustainable organizational learning practices that can improve organizations effectiveness and develop its performance through ample qualification, suitable working condition, and potential motivation. Thus, this article aims to emphasize on several approaches of organizational learning as facilitating variables. Today, the strategic part of HRM practices which was integrated within the organization stated that the success of the organizational performance lied in developing positive attitudes of individuals, groups, and organizations that mainly enhanced individual competence as well organizational competence through organizational learning. Therefore, the context of this study identified the key concept of SHRM that influenced and boosted knowledge, skills, and abilities (KSA's) of employees in an organization. Finally, this article recommended some research suggestions based on the highlighted propositions that accelerated organizational performance and improved competitive abilities.
\end{abstract}




\section{Introduction}

Today, it is essential for the businesses to be able to innovate and integrate new knowledge that enables them to achieve sustainable organizational learning and performance development in order to survive and achieve competitive advantage. Therefore, many organizations realize the importance of strategic HRM to build technical infrastructures that allows them repossession and dissemination of knowledge especially where human resources is responsible for empowering the effect of recent trends in organizations and shielding them against the unwanted effects. Hence, SHRM is viewed as an eminent approach to meet some of global challenges. This paper uses two aspects to organize the philosophy and concept of SHRM. It introduces the notion of organizational learning process and offers some insights into how learning might occur at the organizational level in order to enhance organizational competency. On the other hand, it includes all issues related to the people management and all processes which can improve organizational efficiency and enhance organization's performance through hiring right people, leaders, and cultural fits such as adequate qualification, right organization design, change management, appropriate working conditions, performance driven organization, and right people processes for capability development. The background of this study draws upon various approaches and models concerning SHRM where organization's performance development approach includes strategies or actions which are effectively responsive to the changes in its external environment.

Zirak (2015) argued that organizational learning is a concept that has emerged initially during 1970s. Precisely, organizational learning expresses the natural curiosity and desire of individuals to learn within the organizations which enables them to cope with changing tasks, technologies, and environments. From experts' perspective, organizational learning can be considered as an opportunity to make changes and keep pace with the dynamically changing environment (Conner, 1992). This impression highlights that organizational learning is a fundamental factor in stimulating innovation and creativity within the organization.

Therefore, the question of sustainable organizational learning and performance development become crucial elements in assessing and strengthening the overall development of organizational effectiveness. In this changeover condition, the notion of human resource management has become a key aspect of enhancing organizational performance through sustainable organizational learning. Nowadays, human resource management professionals use the term strategic human resource management to convey their thinking that effective strategic HRM contributes to business effectiveness. It also indicates the significance of their interrelationships with other elements comprising an organizational system which includes elements in the organizations as well as the multiple stakeholders who evaluate the organization's effectiveness and determine its long-term survival (Jackson, Randall, \& Kaifeng, 2014).

Consequently, the development of organizational learning seems to be undertaking the challenges created by increased international competition and the growing importance of innovation in the knowledge society. Hence, this paper discusses the key activities of HR 
specialists that involved in operational matters in order to gain knowledge about their firms and assist the line managers to improve their efficiency. It tries to reveal that human resources management enables organizations or firms to understand the value of internal and external customers, competitors' knowledge, products, technology, and sources of competitive advantage. It is essential to ensure that the success of any organization which is based on the belief that an organization gains competitive advantage by using its people effectively and efficiently.

According to numerous HRM scholars' views, it is prerequisite for sustaining organizational competitiveness and enhancing organizational performance. Cohen (2015) mentioned that HR presents the profession with opportunities and even more thought-provoking challenges. Over the past several decades ago, HR has come to be known and transformed into an important profession. It has also become diverged in other ways and states undeniable importance of critical HR functions to address and ensure the success of any organization from a global perspective. In some organizations, HR is considered as a strategic partner, where the most senior HR professionals are regarded and respected in the same fashion as any one of their executive counterparts. In other organizations, HR is only considered as an important administrative function which has a key role in keeping the organization running smoothly and correctly (Vosburgh, 2007).

According to Price (2004), the concept of human resource management (HRM) is the reflection of three key words, namely human, resource, and management which do not provide much enlightenment. The word 'human' implies that it has something to do with people while management refers to business and organization domain. Finally, the word "resource" is a highly ambiguous concept that many people find it difficult to understand. Strategic human resource management (SHRM) is the option, alignment, and integration of an organization's HRM system so its human capital resources most effectively contribute to strategic business objectives (Cascio, 2015). The aim of strategic human resource management is to boost business performance through managing people. It is important to highlight the role of SHRM as a process that involves the use of overarching approaches to the development of HR strategies which are integrated vertically with the business strategy and horizontally with one another. Such kinds of strategies define and determine the plans and intentions which are related to the overall organizational considerations including organizational effectiveness, resourcing, learning and development, rewarding, and employee relations (Armstrong, 2006).

Thus, surveying SHRM in relation to organizational learning and performance development is at an important stage. Its growth is being inhibited by rapid contextualization of HRM, its different inherent values, assumptions, devotions, and philosophies which are taken for granted as important aspects of an organization to enhance the level of its performance. Research has shown that organizational performance and organizational learning are generally not major issues of organizations in performance development. The focus of interest is on training rather than learning even at the individual level which may result in the usual emphasis on formal off-job training rather than seeking opportunities for learning from work. 
Therefore, this paper provides a review of the empirical literature and some common distinctive elements and features of strategic HRM practices and relationships for successful organizations. It tries to present the concepts and the strategies of managing people which are beneficial for organizations by developing cooperation within the learning organization and renovating human resources management approach. Furthermore, this paper states that organizations are capable to achieve distinctive advantages of strategic HRM through applying some strategic features such as organizational development and organizational learning that mediate and enable organizations to sustain and to strengthen their businesses competency.

\section{Theoretical Background of Strategic HRM Approach}

To address the relevance of SHRM in an organization, it would be better to emphasize on current organizations' effectiveness which are always faced with competitive challenges and turn them into business opportunities. Henceforth, HRM function is expected to design, tailor, and implement efficient systems to help internal customers operationalize strategic actions.

In this perspective, human resource management function acts as a service provider which has an effective toolbox to support and help other managers to achieve their goals in line with the organizational strategic goals or orientations (Moustaghfir, 2014). According to Dermol \& Rakowska, (2014), the term of SHRM fits well with the concept of HR strategy due to its ability to create long term value for the organizational performance management and development. Storey (2001) identified that HRM is a distinctive personnel management which seeks to achieve competitive advantage through the strategic development of a highly committed and capable workforce by applying an array of cultural, structural and personnel techniques.

Similarly, it is necessary to state that HRM covers a wide range of activities and variations across occupations, firms, industries, societies, organizational levels, and business units (Boxall, Purcell, \& Wright, 2007). Boxall introduced the main characteristics of HRM consist of being diverse (hard or soft), strategic, business-oriented, focusing on mutuality, taking a unitary view, and treating people as assets or human capital.

\section{Organizational Learning}

The notion of organizational learning is presently subject of much ongoing debates between behaviorists and economists. In the book "a behavioral theory of the firm", Cyart and March (1963) introduced the concept of organizational learning initially. They stated that organizational learning is a field of academic research and professional practice with a relatively recent development. Therefore, the companies should learn from their experiences with the intention of adapting themselves to the conditions of the environment.

Practically two separate literatures have been developed in the arena of business and management. One of them consists of some scholars and practitioners who are trying to clarify, develop, and operationalize the concept more and other one which is the recent management science trend and known as potentially profitable managerial skill includes professional and 
academic writers who perceive organizational learning as the learning organization. The strategies of HRM consist of better organizational learning, organizational innovation, knowledge management capability which ultimately contributes to achieving organizational performance, organizational learning which improves organizational innovation and accumulates knowledge management capability, organizational innovation results in knowledge management capability development, and technological companies which should use organizational knowledge in order to enhance organizational performance (Kou, 2011). This paper tries to categorize the perception of organizational learning based on various management scholars and experts' perspectives.

According to Wei et al. (2014), there are two kinds of organizational learning including exploitative and exploratory learning which are crucial for moderating the relationship between managerial ties and opportunity capture. Exploitative learning refers to the learning from the current knowledge within the organizations base on the refinement and extension of existing competences, technologies, and paradigms, whereas exploratory learning refers to the learning related activities to acquire new knowledge beyond the organizations for experimenting new options or alternatives. Jones (2001) offered some insights into how learning might occur at the organizational level where the elements such as organizational culture, development of critical thinking and reflection skills, regular reflection opportunities, exploring continuous learning opportunities, taking action, and reflecting critically on outcomes and actions are considered important in organizational learning processes. Robelo and Gomes (2011) defined organizational learning as a process within an organization which empowers it to acquire, attain, and modify organizational memory through providing directions for organizational action.

\section{Strategic HRM as a Factor for Enhancing Organizational Performance}

Stankard (2002) provided a universal definition for organizational performance which stated that it is the final product of different regions or units' interactions in the establishment. Organizational performance refers to the effects of various organizational processes which take place in the form of its routine operations (Hussein et al., 2014). SHRM and organizational learning can encourage an organization to satisfy their goals and also enable them to improve their level of performance and organizational functioning. In line with other previous studies, Richard et al. (2009) stated that organizational performance is one of the most important constructs in management research that covers the actual output of an arrangement as it valued by the planned outputs and objectives of an organization to maintain their sustainability. Sebhatu (2010) indicated that the management increasingly tries to find the ways to improve sustainability of their performance through identifying, managing, and measuring the drivers of improved sustainability and the systems and structures that can be created to improve their performance.

Organizational performances can be raised through individual competence, group competence, and organizational competence within an organization that facilitate organizational learning through its positive effect on managerial skills which mediate the relationship between 
sustainable organizational and performance growth, review of relevant literature about the relationships between organizational learning and performance development, and distinctive explanation by different scholars. Highlighting the concept of strategic HRM and its purpose and practice which diverge from one system to other based on organizational issues is necessary.

To better comprehend the nature of SHRM, this paper attempted to propose some common elements or features of organizational learning practices for performance development through reviewing the relevant literature and available project documents. It proposes some distinguishing factors for successful practices of organizational learning and its competency, better interpersonal relationships, and internationalization and externalization of knowledge. Moreover, it enables organizations to develop the sustainability of their organizational performance and enrich institutional capability and performance which hasten progress towards achieving the sustainable competitive advantage.

\section{Strategic HRM: Definitions and Perspectives}

The primary goal of this survey is not mere investigation of different researcher's opinions over competitive advantage that has shifted from tangible and physical assets to a more intangible and knowledge-based assets where knowledge has become the major driver of business performance which is handled, developed, leveraged, and employed as a key capability. Most of such resources are primarily placed in our learning abilities as human beings because they are generated, enriched, and nurtured primarily through social interactions and collective dynamics that's why the human resource management performs as a fundamental core competency in both secret and public organizations (Moustaghfir, 2014).

Thus, this paper emphasizes primarily on those approaches of SHRM which can be classified under the name of sustainable organizational learning and performance development including sustainable growth of employees' individual capability which enables organizations to strengthen their methodical plan and ability to create something better (scientific excellence) as well as increasing innovation capacity. The narrower definition is also accepted which may be compatible with the conceptual reinforcements of the HRM's strategic approach within a programmatic framework about how the organizations' goals will be achieved through applying HR strategies and integrated HR policies. To face such competitive challenges and transform them into business opportunities, HRM function is required to design, fit, and implement efficient systems to aid internal customers operationalize strategic actions.

In this view, the function of human resource management performs as a service provider providing an effective toolbox to support other managers and aid them attain their targets in line with the organizational strategic goals and orientations.

Therefore, research on relationship between strategic HRM and business performance has dominated the academic and practitioner debate for more than two decades. Nevertheless, most subjects and publications in the field of HRM have defined the concept in terms of private patterns. Noe, Hollenbeck, Gerhart, and Wright (2012) argued that HRM practices and policies can influence employees' behaviors, attitudes and performance. They are centralized on several 
important practices which can positively impact organizational performance such as human resource planning, recruitment, selection, training and development, compensation, and performance management and employee relations (Cania, 2014; Moustaghfir, 2014). In order to be comprehensive within a specified time frame, the empirical phase of the study has been done on the basis of different academic experts' opinions under the EU framework program for research and innovation. A few comparative studies have been conducted on the basis of preliminary research undertaken by renowned HRM experts where they have attempted to add value through insights that have emerged on the SHRM and organizational learning approach. The findings of this study manifested the distinctive features of SHRM approach, advantages and goals of organizational learning, synergies between learning organizations' different priorities and aspects that facilitate the sustainable organizational learning and organizational competitiveness.

\section{Method}

This study primarily addressed the combination of both empirical evidence and inductive reasoning. Empirical argument depicts the methods of acquiring the knowledge. Generally, the inductive reasoning shows the level of sustenance in the form of probabilistic reasoning and the source of most scientific theories based on the contemporary approaches of strategic HRM.

\section{Results and Discussion}

This study was conducted to explore the potential contribution of HRM strategy and its distinguishing features to gain some competitive advantages and enhance organizations' capacity and performance in relation to the implementation of organizational learning strategies (know-what, know-why, know-how and know-who).

According to the findings of evolutionary economics, organizational behavior and HRM literature have generally given a comparative perspective to us about the conceptual aspects of SHRM and the key priorities of organizational learning which has a great impact on organizational success and enhance competitive advantage.

Figure 1 depicts that SHRM approach as a key instrument which fosters sustainable organizational learning and improves the organizational performance due to the presence of organizational learning attributes and priorities which complement and facilitate the community participation or involvement within the organization. Alternatively, SHRM advantages reinforce managerial skills such as individual, group, and organizational competence in an organization through improving organizational learning including individual, group, and organizational learning and human resources development which leads to promote innovative capability and business growth due to their intrinsic competences. 


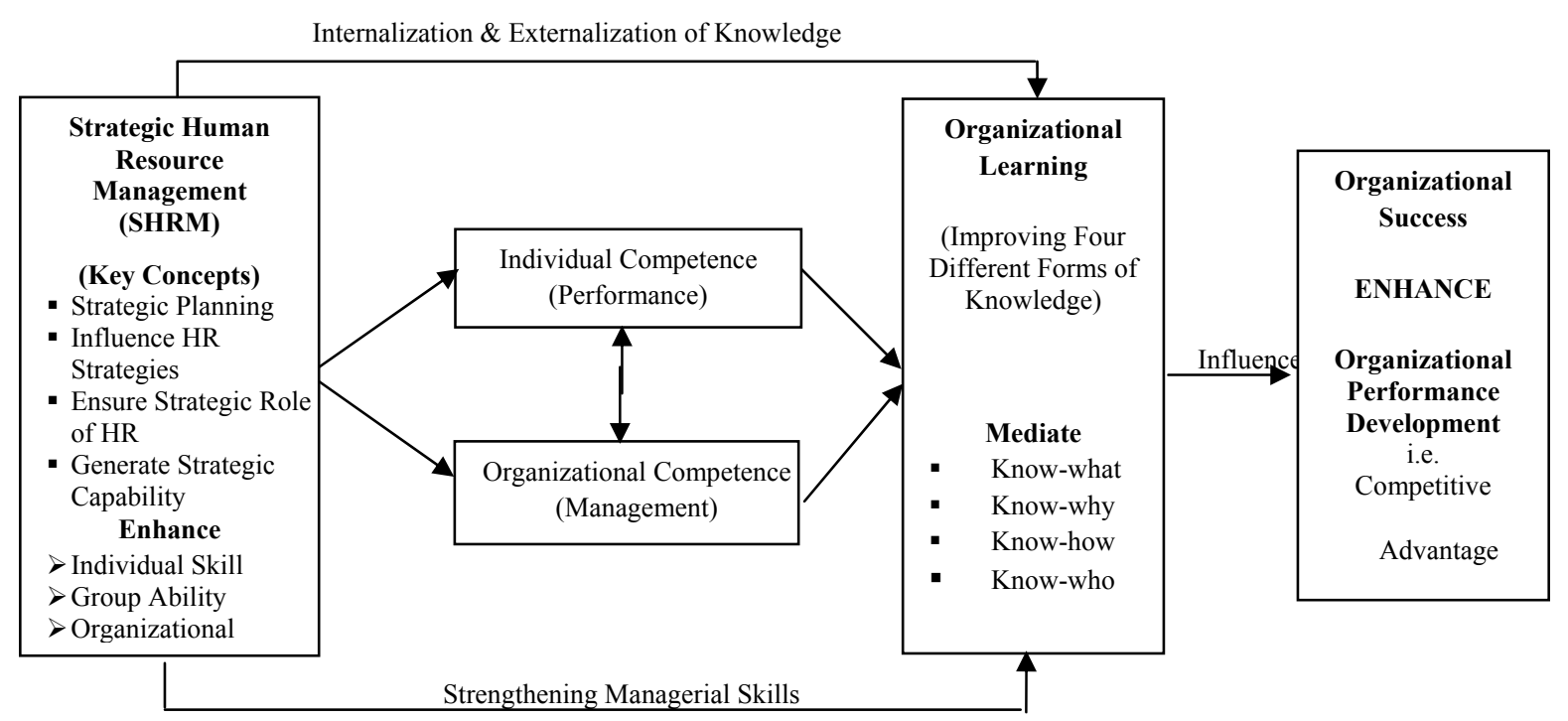

Figure 1. Thematic model of organizational performance development in relation with SHRM and organizational learning objectives

Figure 1 illustrates the thematic model of organizational performance development in relation with SHRM and organizational learning objectives which is the synergic effect of both individual employee competency (performance) and organizational competency (management) that leads to develop organizational success and performance indicators for sustainable development competitive advantage. Furthermore, Figure 1 shows that organizational performance development is being influenced by rapid contextualization of organizational learning which acts as a mediator and improves four different types of knowledge among individuals, groups, and organizations including know-what that means knowing the facts, know-why which means understanding the principles and laws of internal and external business environments, know-how which means having awareness of skills, abilities, and knowledge of individual as well as group employees for making something, and finally knowwho which means knowing the capable person who performs and manages deliberately.

In short, it is necessary to highlight the significant features of the organizational performance development strategy in relation with organizational learning which represents the key aspects of SHRM. As a result, the strategic HR reinforces the managerial knowledge, skills, and abilities (KSAs) of an organization through internalizing the idea and attitudes such as behavioral development of individual employees within the organization and externalizing such as articulation of tacit knowledge. During knowledge creation process, organizations not only enrich their technical and operational skills but also accomplish them through improving organizational learning and building organizational capacity in order to enhance organizational performance.

The positive impact of SHRM's competencies accentuates organizational performance in order to justify whether the presence of SHRM can really influence the organizational performance enhancement (excellence) to achieve the competitive advantage or not, whether HRM activities support the development of managerial skills and organizational competences 
or not, and whether the initiatives provided by the HR system in the organizations are effective or not.

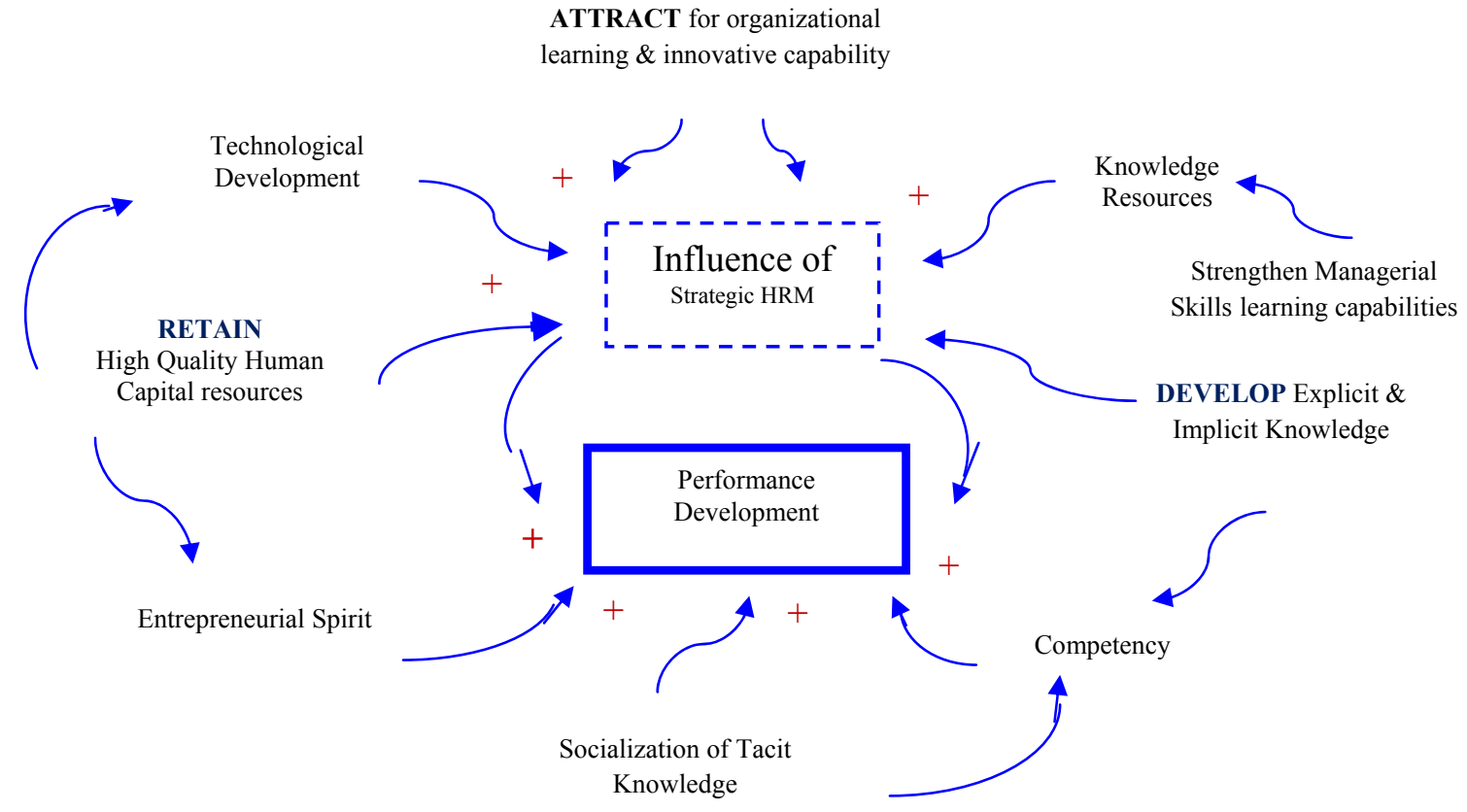

Figure2. The positive influence of SHRM enhancing organizational performance

Moreover, Figure 2 reveals how the existence of sufficiently qualified people (innovation), the right type of working environment (organization), and right enthusiastic people (motivation) will directly as well as indirectly induces the development of human resources at business through retaining, developing, and attracting the right kind of people, place, and passion. This manifests strategic human capital flow which reveals continuously positive reactions to meet the competitive forces and the consequences of the present business environment. This article justifies that the accomplishment of the organizational performance development lies in positive attitudes of individuals, groups, and organizations that mainly enhancing individual competence (performances) as well as organizational competence (management) through organizational learning. The context of this study identifies the key concept of SHRM that influence and boost knowledge, skills, and abilities (KSA's) of employees in an organization (individuals, groups, and organizational proficiency).

To refine the thinking about HRM value creation by individual employees at the organization level of analysis, Bruce Kaufman (2001) clearly expressed the excellence, association, and amalgamation of an organization's HRM system and argued that human capital resources most effectively contribute to strategic business objectives. Reviewing the relevant previous studies such as Fombrun, Tichy, and Devanna (1984), Beer, Spector, Lawrence, Mills, and Walton (1984), Cascio and Boudreau (2012), Paauwe, Guest, and Wright (2013) shows that HRM focuses on describing and understanding HRM firm performance relationships. Beer et al. (1984) articulated that "the aim of introducing human resource management into the strategic arena is not to enhance the status of traditional personnel- 
resource staff, but rather it is to alter the way managers set priorities and make decisions" (p. 26).

In contrast, Kaufman (2001) emphasized on SHRM and firm performance as a sciencebased model where organizations and HRM are studied as if a laboratory setting with much less priority on experiential contact and practical results and much greater emphasis on analytic theory development. Boxall (2013) worked on alignment in HR systems as well as Collings (2014) who worked on strategic role of HRM and introduced the idea of alignment in terms of individual capability, group capability, organizational capability, and their commitments and contributions. Collings and Mellahi (2009) stated that strategic talent management plays an important role in systematic identification of key positions which differentially contribute to the organization's sustainable competitive advantage, the development of a talent pool of high potential and high performing incumbents to fill these roles, and the development of a differentiated human resource architecture to facilitate filling these positions with competent incumbents to ensure their continued commitment to the organization. Applying such kind of thinking to the issue of SHRM leads to the formation of following four important research propositions or RPs such as RP1which states that SHRM is the key factor in HR development systems, RP2 in which individual employee's proficiency (KSAs) creates value through their individual creativity, RP3 which expresses that organizational learning is used to strengthen the professional skills, and finally RP4 remarks that organizational success enhances performance development.

RP1 indicates that HR system in an organization which is created by individual talent, group talent, and organizational talent outweighs the value which is shared with them by motivation, integration, and collaboration, provides sustainable gains over the time, and balances the efforts for managing competence, namely management skills or expertise in order to maintain and extend the organizational success in the sustainable long-term performance.

This research proposition, RP2, tries to highlight that individual competence has some special value in an organization which can enable firms to create novel tasks, services, and business models. The investors believe that talented people have skills to outpace in existing resources and skills to improve organizational proficiency (generate organizational strategic capability).

RP3 emphasizes that organizational learning helps strengthen the firms' competitive skill through improving four different types of knowledge. This knowledge development process categorizes information by answering the following queries like what the important factor for organizational development is (Know-what), why it is necessary to achieve (Know-why), how it will be potential to make it (Know-how), who will be the right person to accomplish this task (Know-who) that can enhance organization's sustainability through internalization and externalization of knowledge (organizational performance). RP4 tries to demonstrate the synergic effect of SHRM and organizational learning and its influence on performance development. It specifies the continual process of organizational development in relation with the distinctive features of SHRM where organizational learning has a mediating role in improving organizations explicit and implicit knowledge which empower the firms to maintain 
the sustainable organizational learning for enhancing the level of organizational performance, namely sustained competitive advantage.

\section{Conclusion}

It is essential to accentuate the fact that the manifestation of SHRM concept as well as the significance of organizational learning has been concerned with the perception of organizational performance development strategy. It seeks to increase the efficiency and effectiveness of HR systems, organizational behavior, and constitutes a leading concept which acts as a vital stimulant for the individual and group competency development in relationship with the organizations' learning strategy and organizations competency development strategy in order to accomplish sustainable organizational learning and performance development. In this study, the observed propositions show that the key dimensions of the present business environment focused on right kind of people at right time and at right place in order access proper KSAs, innovative capability of the individual employees and technological expansion where the presence of SHRM approach plays a key role in enhancing capacity and building learning organizations by the emergence of knowledge creation process between the individual, group, and organizations. Nevertheless, it is significant to specify that simultaneously organizational learning and performance enhancement strategies also play a crucial role in enabling the business institutions to enhance their core competencies through interaction between individuals and use of estimates of the pooled information within an organization. It is presumed that the value-added process of knowledge development will lead the businesses organizations to attain their competitive advantages through the transfer of specific individual knowledge to the collective knowledge and vice versa.

Successively, the directed study highlights the prominence of HRM and implementation of HR activities which reduces communication and networking gaps and deficiencies between the organizations to alleviate the strain through novelty or innovation, association, dedication, and motivation between organizations where organizational learning and performance enhancement approach appear as a critical factor for the successful managerial skill development and capacity enhancement. Though, it has been observed that both of these approaches have significance effect all over the world. Today is not only to improve the individual employees' competitiveness and institutional competitiveness, but also to find out the way how they can sustain and survive with their organizational learning and enhance the performance level with their prevailing resources to compete in this ever changing dynamic world.

Addressing all potential key positive facets of SHRM demonstrates some valuable features for instance in this study. It is a flexible process of developing a sense of direction, making the best use of resources and ensuring it with strategic fit. It also encourages foreseeing the organizational capability of a firm which depends on its resource capability. Moreover, it generates the best organizational managerial capability through ensuring that the organization has the skilled, engaged, committed, and well-motivated employees in order to achieve sustained competitive advantage. Finally, it delivers added value and advantages to achieve sustainable competitive advantage through the strategic development of the organization's rare which is hard to imitate and hard to substitute human resources. 


\section{Acknowledgment}

The first author is thankful to the Director of University Institute for providing management support system (MSS) and infrastructural facility to carry out this research. Also, the first author dedicates this study to her only beloved son "Kanishka Binayak Saha".

\section{References}

Armstrong, M. (2006). Strategic human resource management: A guide to action ( $3^{\text {rd }}$ ed). USA: Thomson-Shore, Inc.

Beer, M., Spector, B., Lawrence, P. R., Mills, D. Q., \& Walton, R. E. (1984). Managing human assets. New York: Free Press.

Boxall, P. F., Purcell, J., \& Wright, P. (2007). The goals of HRM. In P. Boxall, J. Purcell, \& P. Wright (Eds.), Oxford handbook of human resource management (pp. 48-67). Oxford University Press, Oxford.

Boxall, P. (2013). Mutuality in the management of human resources: Assessing the quality of alignment in the employment relationship. Human Resource Management Journal, 23(1), 3-17.

Cania, L. (2014). The impact of strategic human resource management on organizational performance. Economia Seria Management, 17(2), 373-383.

Cascio, W. F. (2015). Strategic HRM: Too important for an insular approach. Human Resource Management, 25(3), $423-426$.

Cascio, W., \& Boudreau, J. (2012). Short introduction to strategic human resource management. New York, NY: Cambridge University Press.

Collings, D. G. (2014). Toward mature talent management: Beyond shareholder value. Human Resource Development Quarterly, 25(3), 301-319.

Collings, D. G., \& Mellahi, K. (2009). Strategic talent management: A review and research agenda. Human Resource Management Review, 19(4), 304-313.

Cohen, D. J. (2015). HR past, present and future: A call for consistent practices and a focus on competencies. Human Resource Management Review, 25(2), 205-215.

Conner, D. R. (1992). Managing at the speed of change: How resilient managers succeed and prosper where others fail. New York: Villard Books.

Cyert, R. M., \& March, J. G. A. (1963) A behavioral theory of the firm. Englewood Cliffs, NJ: Prentice Hall.

Dormal, V., \& Rakowska, A. (2014). Strategic approaches to human resources management practice. Bangkok: To Know Press.

Fombrun, C., Tichy, N., \& Devanna, M. (1984). Strategic human resource management. New York, NY: Wiley.

Hussein, N., Mohamad, A., Noordin, F., \& Ishak, N. A. (2014). Learning organization and its effect on organizational performance and organizational innovativeness: A proposed framework for Malaysian public institutions of higher education. Procedia -Social \& Behavioral Sciences, 130, 299-304.

Jackson, S. E., Randall, S. S., \& Kaifeng, J. (2014). An aspirational framework for strategic human resource management. The Academy of Management Annals, 8(1), 1-56.

Jones, M. L. (2001). Sustainable organizational capacity building: Is organizational learning a key? International Journal of Human Resource Management, 12(1), 91-98.

Kaufman, B. (2001). The theory and practice of strategic HRM and participative management. Human Resource Management Review, 11(4), 505-533.

Kou, T. H. (2011). How to improve organizational performance through learning and knowledge? International Journal of Manpower, 32(5/6), 581-603.

Moustaghfir, K. (2014). Strategic human resource management: An HR planning toolkit In V. Dermol \& A. Rakowska (Eds.). Strategic approaches to human resources management practice (pp. 27-51). Poland: To Know Press.

Noe, R. A., Hollenbeck, J. R., Gerhart, B., \& Wright, P. M. (2012). Fundamentals of human resource management (5 ${ }^{\text {th }}$ ed.). Boston, MA: McGraw Hill/ Irwin.

Paauwe, J., Guest, D., \& Wright, P. (2013). HRM and performance: Achievements and challenges. Chichester, Sussex: Wiley Blackwell.

Price, A. J. (2004). Human resource management in a business context $\left(2^{\text {nd }}\right.$ ed.). London, UK: Thomson Learning. 
Rebelo, T. M., \& Gomes, A. D. (2011). Conditioning factors of an organizational learning culture. Journal of Workplace Learning, 23(3), 173-194.

Richard, P.J., Devinney, T. M., Yip, G. S., \& Johnson, G. (2009). Measuring organizational performance: Towards methodological best practice. Journal of Management, 35(3), 718- 804.

Sebhatu, S. P. (2010). Corporate social responsibility for sustainable service dominant logic (Doctoral dissertation). Karlstad University, Karlstad.

Stankard, M. F. (2002). Management systems and organizational performance: The search for excellence beyond ISO9000. Westport, CT: Greenwood Publishing Group.

Storey, J. (2001). Human resource management: A critical text ( $2^{\text {nd }}$ ed.). London: Thomson Learning.

Vosburgh, R. M. (2007). The evolution of HR: Developing HR as an internal consulting organization. Human Resource Planning, 30(3), 11-23.

Wei, Z. et al. (2014). Organizational learning ambidexterity, strategic flexibility, and new product development. Journal of Product Innovation Management, 31(4), 832-847.

Zirak, A. (2015). Implementation of learning organization components in Ardabil social security hospital. International Journal of Organizational Leadership, 3(4), 200-212. 